\title{
Introduction
}

My interest in whales, like with most New Zealanders, began at a very young age. However, despite an interest in this species my academic work initially took me in different directions within international environmental law. As such, it was only in 1997 that I was first invited to assist the New Zealand delegation at the International Whaling Commission (IWC) meeting for the following year in Oman. Since this time, my interest in the whaling debate and involvement in the discussions at both the IWC and elsewhere has only broadened. In many ways, this book is about these discussions.

When I first became involved, I was somewhat befuddled by the spectacle that I saw. In some ways, the international focus on environmental issues had moved on to newer developments - developments which were not even imagined when the IWC became a central focus of international concern in the early 1970s. However, in other ways, the focus on whales is as intense as ever, and the public interest in this debate has not shown any sign of weakening. Trying to understand why this issue retains such a prominent concern in the twenty-first century, despite more than two decades of bitter confrontation between opposing signatories to the convention - and no settlement of differences on so many issues - can only be fathomed when the issues are disentangled. When this is done, it quickly becomes apparent that the whaling debate is very different from many comparable altercations on environmental policy, because it involves so much. It is true that the whaling debate is fundamentally about whales, but it is also about questions of ethics, politics and law. There is no one primary concern within the altercations of the IWC, and at times it seems like a forum with a dozen or so unrelated, highly contentious issues battling back and forth. It is my hope that the chapters in this book will begin to explain to the interested reader exactly what is going on, and why.

This book is broadly divided into three parts, followed by a conclusion. Part I deals with the numbers of and threats to cetaceans at the present time. Part II examines what I consider to be underlying ethical issues relating to cetacean questions at the IWC. Part III investigates what I have labelled the 'mechanics' of international law. Although these parts and the chapters within them are presently separately, it is important to realize that they are all very much interconnected, and together, they make up one of the central debating grounds in international environmental law and policy. 


\section{NUMBERS AND THREATS}

With regard to current threats to the overall status of whales, four chapters are offered. Chapter 1 seeks to show the reader a brief history of the whaling debate throughout the twentieth century, and an introduction to some of the key underlying concepts, with a particular emphasis on the international mismanagement of cetaceans before the commercial moratorium came into operation in 1986. Chapter 2 is primarily focused on how individual species have been managed, and gives an estimate of their current population abundance.

Chapter 3 suggests that a foremost threat for a number of species, and cetaceans in particular, in the new century is environmental change to the oceans they inhabit. As such, understanding the health and management of the oceans is essential to any meaningful comprehension of the scope of the problems ahead in this field. To further this goal the chapter has two objectives: to examine the environmental threats that are posed to cetaceans; and to display the way the international community has begun to deal with them. It is necessary to examine the broader response of the international community in general, as ultimately, the resolution of most of these difficulties will be achieved in other issue-specific forums, and not the IWC. This is unfortunate, as in regard to the problem of environmental threats, the IWC may be losing part of its ability to ultimately fulfil its mandate. This problem is doubly troubling, as many of the other forums have had only limited success in protecting the environmental health of the oceans. This chapter seeks to show the environmental threats, overlaps with other forums and the lacunas that exist.

The fourth and final chapter on 'threats' to cetaceans deals with bycatch. The bycatch of cetaceans is a growing problem, and is one which has been largely neglected until recently. However, since becoming apparent with regard to the management of cetaceans, it has also become highly noticeable in a number of other international wildlife forums such as those dealing with, inter alia, seabirds, turtles and sharks. Due to the fact that bycatch is not a new problem, and is a difficulty which the international community has tried to deal with over the last 150 years, it is possible to learn from their experiences and apply the principles which have been successful elsewhere, and in 2001 the IWC passed a resolution adopting these principles. The first principle is to be very accurate about defining the target species, and being willing to modify, if not abandon, technologies which are indiscriminate in their capturing. Assuming that technology cannot entirely prevent incidental catch, it is necessary to have a collection of secondary mechanisms in place. These suggest that if the incidentally caught species is alive (and assuming it has a good chance of survival), it should be released. Second, harvesting operations need to have direct quotas on how much bycatch they may take before having to cease cos $_{81845425616}$ 
harvesting. Finally, when species which are the subject of separate conservation measures are ensnared as bycatch, they should not be landed and profited from. However the bycatch should be retained (not discarded at sea) and disposed of appropriately. Conversely, with bycaught species that are not the subject of concern under conservation regimes, their active utilization (rather than wasting them) should be considered. However, although the utilization of this form of bycatch should be pursued, it is important that those who caught it are not directly rewarded for the process.

\section{PHILOSOPHY IN INTERNATIONAL ENVIRONMENTAL LAW}

The chapters on humane killing (Chapter 6), scientific whaling (Chapter 5), the option of non-utilization in international law (Chapter 7) and so-called aboriginal subsistence whaling (Chapter 8) fall into what I broadly consider philosophical questions. In the first of the three chapters in this area (humane killing, scientific whaling and lethal non-utilization) Japan, Norway and a number of countries aligned to their views consistently argue that each one of these is trying to introduce 'new' things into the IWC. Moreover, these new things are often culturally relativistic and without precedent in international law. I try to counter all three of these arguments by demonstrating their consistent history within the IWC, recognition in national law and philosophies, as well as within comparable international law. The ideal is to make the reader realize that ethics is at the forefront of many of these discussions within the IWC.

On the question of humane killing, Japan and a number of like-minded countries have argued that any attempt to put humane killing considerations squarely within the considerations of the IWC is ultimately ultra vires, as it has no history within the IWC, is culturally relativistic and without precedent in international law. In my thinking, this argument represents the bottom line of ethical demands within international wildlife law. To argue against this bottom line is to ultimately suggest that humanity has no moral considerations, beyond the survival of the species. To argue this goes against nearly five decades of recognition of the consideration within the IWC, a vast collection of diverse philosophical and national concerns which recognize the legitimacy of humane killing concerns, and an emerging corpus of international wildlife law which recognizes that mitigating against unnecessary cruelty is a worthwhile and necessary goal.

The second area where ethics are paramount is with regard to scientific whaling. This area, in which legal rights have conflicted directly with necessary social limits, has become one of the major flashpoints in the IWC. 
Moreover, this debate has direct implications in numerous overlapping national and international bodies, in which the quests of scientific knowledge come up against the legitimate limits of society, in both national and global settings. These areas range from so-called 'animal testing' debates, through to areas where one species is scapegoated for the decline of another species which humans wish to harvest. In this instance, the question is how far can scientific pursuits be allowed in the utilization of non-human species? To answer this question, the chapter examines the way in which numerous philosophical considerations have combined to suggest that the utilization of animals for scientific purposes is only permissible if no alternatives to animal utilization exist, and the information obtained has an overall merit which is needed. This broad philosophical basis has formed the core of multiple national laws, and has found its way into many international codes. Moreover, it is basically the bottom line of the IWC. However, some countries have acted against this ethical backdrop for over 15 years.

The third area where ethical concerns need to be dealt with has to do with the overall question of whether whales which are not endangered should be hunted or not. Chapter 7 deals with this argument, and shows that there are two diametrically opposed views on this question. One assumes that sustainable hunting is legitimate, and the other argues that even if it is legitimate, that does not necessarily mean it should be pursued. The foremost place where this debate has emerged, has been with the so-called 'Irish Proposal', of which the central issue is - to make the high seas into a global sanctuary for all whales. Although the Irish Proposal allows the idea of coastal whaling (something which the international community has limited authority over due to the exclusive economic zones of coastal states) the idea to turn the high seas into a sanctuary is radical. It is radical because it would involve opting for a non-lethal utilization of cetaceans - irrespective of their conservation status. A number of countries have argued that this is illegal and not possible within international law. However, this view is mistaken, as it is exactly what the international community did when it decided to make Antarctica into, effectively, an international wilderness park that would not be utilized by conventional means. Accordingly, the international community has already once decided that sometimes the best way to 'utilize' something, is not to pursue traditional utilization paradigms.

The last chapter in this philosophy part deals with aboriginal subsistence whaling (ASW). I have included this chapter to demonstrate the difficulties of defining indigenous peoples in international law, and how their causes and legitimate needs have been manipulated, within a forum which has struggled to deal with overlapping considerations of anthropology, philosophy, conservation and international law. This has happened as a number of countries have attempted to stretch this category beyond anything that was initially planned 
for. Accordingly, traditional limits surrounding this category, such as noncommercial utilization, nutritional need and local consumption have become increasingly slippery and difficult to answer. However, these issues are relatively simple when compared to the question of how 'indigenous culture' itself fits into the IWC, and underlying assumptions of exactly what this is are explored. This becomes increasingly difficult when considerations of limits on such cultures (from humane killing to catch limits because of the severe endangerment of the stock) are considered.

\section{THE MECHANICS OF INTERNATIONAL ENVIRONMENTAL LAW}

Chapter 9 deals with the mechanics of international law, and how treaties evolve. Sanctuaries have a long and distinguished history within international law. In the last fifty years, the reasons for the creation of sanctuaries have expanded into more holistic considerations. However, when the International Convention on the Regulation of Whaling (ICRW) was drafted, this broader approach was not in currency. The establishment of sanctuaries has had to be achieved within the much narrower bounds of the text of the convention. On a prima facie level, arguments may be adduced that there is a scientific basis for the Southern Ocean Sanctuary (SOS) or the South Pacific Whale Sanctuary (SPWS) and that they have a purpose to play alongside the revised management procedure. As such, the strict requirements of the ICRW can be fulfilled. On a secondary and somewhat deeper level, it is possible to justify the SOS and SPWS via a method of statutory interpretation of the convention's text which reflects that although the language of the convention has not changed, the way it has been interpreted has. Via this approach, it is possible to construe the terms 'optimum use', 'best interests of the whaling industry' and the 'interests of the consumers of whale products' (the key phrases within the text) in non-consumptive ways. This type of interpretation may be supported under rules within international law, if examples of previous practice demonstrating interpretative usage within such a context can be cited - clearly, the earlier Indian Ocean Sanctuary and the moratorium do this. As such, the SOS may be regarded as being both a legal and an authoritative example of the way in which the majority of the international community has viewed one area of global environmental concern.

Chapter 10 also deals with the workings of international law, but this time with small cetaceans as the case study. Small cetaceans have been a focus within the IWC since the early 1970s. Since this time, the IWC has slowly brought the focus of its scientific committee to examine the status and trends on a number of these species. From such information, it has issued resolutions 
calling for restraint, often directed to specific countries, where the species are clearly at risk. However, opposing this rise in interest in small cetaceans, a number of countries have continually objected, suggesting that any questions regarding small cetaceans are ultra vires. This is because the IWC was not given the authority to examine this issue within the ICRW. The alleged proof for this is that small cetaceans were not originally singled out for coverage, nor were they listed in the nomenclature. This approach is misplaced due to a number of reasons. First, the language of the convention, unlike the earlier whaling conventions, encompasses 'all' types of whales and whaling. Second, the idea that the nomenclature is anything more than a 'guide' is misplaced. To argue otherwise, is to implicitly try to limit the evolution of the ICRW, through the will of a three-quarters majority acting in accordance with the schedule.

A second area which has a strong focus in Chapter 10 is the IWC's relationship with the United Nations Conference on the Law of the Sea (UNCLOS). This question arises because of the assertion that only coastal states - and not the IWC have complete competence over small cetaceans. This contention is typically bolstered by the UNCLOS. However, this is mistaken as the UNCLOS does not accord to coastal states a complete sovereignty in territorial seas. Rather, it affords them a limited sovereignty, and requests nations to co-operate in international forums with regard to a number of related issues. The primacy of the IWC as the forum in question, was clearly recognized in Agenda 21 at the 1992 Earth Summit. This is not to suggest that decentralized approaches to the management of small cetaceans are not important. Rather, the point is that regional organizations need to be complementary to the primary international organization (the IWC) in this area. The regional ASCOBANS and ACCOBAMS agreements are strong examples of this.

Chapter 11 deals with the clashes between international organizations (IOs), or in this instance, between the IWC and the Convention on the International Trade in Endangered Species (CITES). The solution to the problem where CITES has tried to act against the wishes of the IWC can be found in international law, whereby questions of procedure and precedence are established for such situations. These rules, which have been followed in the IWC's relationships with other international organizations, such as the Convention on Migratory Species, and the Convention on the Conservation of Antarctic Marine Living Resources. However, although the same rules have been built into CITES, as this organization has evolved, it has increasingly turned against them, and become a forum in which disgruntled members of the IWC have attempted to overturn IWC decisions in CITES. This chapter argues against this situation, and seeks to make clear the primacy of the IWC in all matters relating to cetaceans, from which other IOs are obliged to follow. Failure to recognize the ideal of precedence in this situation also has large ramifications for other debates between competing IOs as disgruntled members of one IO go 
'forum shopping' to other IOs in search of a more satisfactory result. The damage to international law and order could be massive.

The focus of Chapter 12 pertains to the discussions revolving around the IWC's attempts to secure a new inspection and observation regime. In this instance, the IWC is trying to catch up with international developments in this area, which have occurred in multiple other international and regional fisheries bodies over the last twenty years, since commercial whaling (and the traditional inspection and compliance regimes) has been redundant. The new developments that need to be adopted to make the IWC consistent with international best practice, and supplement the traditional compliance regimes such as vessel identification and foreign observers, are technologies such as vessel monitoring schemes, catch documentation schemes and DNA registers, so as to distinguish illicitly taken whales in the marketplace. Once the illicit catch can be identified, then it will become important for the IWC to revert to its traditional practice of restricting market access to wrongfully taken whales.

Chapter 13 deals with the issue of reservations to treaties. This became a controversial issue within the IWC in 2001, when Iceland, which had earlier been a member of the IWC but later left, attempted to readhere to the ICRW. However, its attempted readherence was refused on a majority vote by the IWC because of the 'conditional' reservation to the schedule which is attached to the ICRW. On rejection of its membership, Iceland raised a number of allegations, suggesting that the IWC's actions were inconsistent with international law. This chapter challenges Iceland's assertions, and shows that the IWC acted in harmony with international doctrine on this question.

Chapter 14 deals with transparency in international law. There are three areas which lend themselves to an analysis of the success of the quest for transparency of the IWC. The first of these relates to non-governmental organizations (NGOs). As it stands, the IWC is operating on a procedural system which is somewhat unique by comparison to other international forums. Although progress has clearly been made in allowing NGOs to increasingly witness what goes on within the IWC and most of its committees, the abilities of NGOs to fully contribute are limited in comparison to other forums. Moreover, a backlash is developing from some member countries against some NGOs within the IWC. With regard to media experience, although it has taken five decades, the IWC has increasingly opened its doors to external media attention. Likewise, with the issue of secret voting, despite a number of attempts to introduce increased secrecy into the IWC, these have been defeated and, as such, a degree of sovereign accountability has been maintained.

So-called 'vote-buying' is the subject of Chapter 15. Vote-buying is something which has become connected to the 'conditions' that countries attach 
when giving foreign aid. This has become a big issue at the IWC, where votebuying was recognized as the antithesis of good faith, good neighbourliness, and any form of reasonable diplomatic practice. However, although this has been conceded within the IWC, the question now becomes: where to from here? The answer to this question is in two parts. First, the problem of votebuying must be identified as being squarely rejected by the international community. Second, mechanisms to deter this practice need to be invoked.

The last chapter in this part (Chapter 16) deals with a debate which has bedevilled the IWC for decades - that of how to fund the organization. One of the more vocal suggestions of late has been to adopt the UN scale of contributions. However, this proposal, like many others examined by the IWC, fails to incorporate principles that have evolved in international administrative law which are much more innovative and dynamic than the earlier blunt approaches based upon compulsion for members, irrespective of benefits or causation of problems. A suitable solution for the IWC would be a division of its budgets into administrative and operational segments, broadly in accordance with the practices of other comparable international organizations.

Finally, Chapter 17 offers a brief conclusion. 